\section{Macroeconomía y conciliación familiar: el impacto económico de los jardines infantiles}

Maria José Bosch, Universidad de los Andes

Carlos J. Garcia Torres, Universidad Alberto Hurtado

Gabriel A. Valenzuela Vicencio, Universidad Alberto Hurtado

Chile es un caso paradójico en su cometido económico en las últimas décadas, si bien ha sido un pais que implemento importantes peño en el mercado laboral es dispar. En efecto, se han obtenido peño en el mercado laboral es dispar. En efecto, se han obtenido modernización de la banca privada y del Estado, reducción de la pobreza, reformas en los sectores sociales, control de la inflación, ción femenina extremadamente baja considerando el importante esfuerzo modernizador realizado en estos años (Figura 1 y Tab 1). La economía chilena estaria desaprovechando una fuente importante del crecimiento económico que sí está presente en otras

conomís con tasas de econimico que si está presente en otras similares. Asi, Chile es un contra ejemplo interesante para otros
paises en desarrollo ylo economias emergentes que buscan modernizar sus economias sin producir imperfección es innecesarias en el mercado laboral, situación que resta potencia y efectividad a las reformas estructurales.

Diversos estudios indican que la causa de esta baja participación laboral femenina en Chile seria una baja conciliacion entre familias y mercado laboral. A modo de ejemplo, un reflejo de las tensiones entre familia $y$ mercado laboral son las actuales ciffas de utilización de prestaciones laborales referidas a las salas cunas y jardines beneficio. Al respecto, existe una importante literatura que relaciona los efectos positivos de la conciliación familiar dentro de las empresas y sus probables efectos no solo en las posibilidades de trabajar de la familia sino también sus efectos en la productividad de los trabajadores y su compromiso con las empresas.

No obstante, desde la perspectiva más macroeconómica, si bien existe un importante reconocimiento del rol de la familia en el crecimiento y ciclo económico, el analisis ha sido más limitado, concentrándose por ejemplo en los efectos positivos sobre la oferta laboral de la familia de un aumento del número de jardines infantiles, del progreso tecnológico que ayudan a las mujeres en el hogar, de shocks que han impulsado la oferta laboral femenina, etc. Si embargo, los efectos sobre la productividad como lo indica la literatura de concilación formilar han sido mayonitariamente ignorados Un estudio reciente de

antiles para conectar los elementos que incentivan la oferta labora vlos elementos que tambièn estimulan en parte la productividad de por fan as en trabajo en la economia chilena. Los autores optan costos de los jardias infe además, se explicita directamente los las empresas.

Un resumen de los resultados del estudio de Bosch (2017), elaMesa por la Inserción Laboral Femenina y el Cuidado de jardines infantes es que un aumento del 1\% en los servicios $0.18 \%$ y el PIB en $0.55 \%$ Si bien los salarios caen inicialmente en $0.12 \%$, estos se recuperan en trimestres posteriores. El principal causante de estos efectos es un aumento de la productividad que umentan en un 0.15\%, impulsando la inversión privada en 0.9\%. En otras palabras, cuando el aumento en los servicios de jardines infantiles es avisado, es decir que ocurrira en un horizonte en que dejan de operar una serie de restricciones y fricciones que opera se a economia, el aumento de la fuerza de trabajo que es causado se transforma efectivamente en más empleo, y con ello impulsa a a I mos a s para acomada mayor cantidad de trabajadores en mayor crecimiento como de una mayor productividad.

En consecuencia, un de las principles conclusiones del estudio de Bosch et al (2017) es que el fuerte aumento del PIB oumbásicamente por el efecto positivo de los jardines infantiles sobre la productividad. Todos estos resultados son obtenidos estimando valores pequeños ylo moderados para las elasticidades que determinan estos efectos. Por ejemplo, la elasticidad que mide el impacto de los jardines sobre la participación laboral está muy por debajo de la evidencia internacional. Además, los efectos sobre la productividad se han restringidos a valores conservadores.

La segunda contribusion del estudio de Bosch (2017) es que los cambios en la composición del financiamiento entre trabajadores empresas se diluyen en la economia a nivel agregado. Esto ultimo o fignif ea, que, a nivel microeconómico, es decir, para una famila levantes. Pero nul, dichos cambios de composición no sean redel financiamiento y explotar los efectos multiplicativos sobe productividad de una mayor conciliación, sin que el cambio especi-

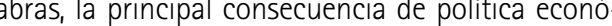
mica es que aumentar los niveles de conciliación tiene importantes efectos sobre la actividad, superando por lejos los costos de su financiamiento. Asl, este estudio presenta evidencia concreta

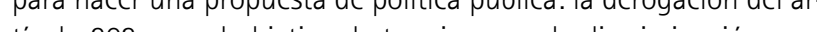
ticulo 203, con el objetivo de terminar con la discriminación contra la mujer, y seguir potenciado la Ley de No Discriminación (Ley


ampliar el uso de los establecimientos escolares a otros horariosy

periodos e incentivar el cuidado infantil, con el objetivo de facilitar REERENCIA

Maria José Bosch, Carlos J.Garcia, Marta Manriquez y Gabriel A. Valenzuea, 2017, Macroeconomia y conciliación familiar: el impacto económico de los Negocios, Universidad Alberto Hurtado.

(2)
FIGURA 1 TASAS DE PARTIIIPACIÓN FEMENINA 2015

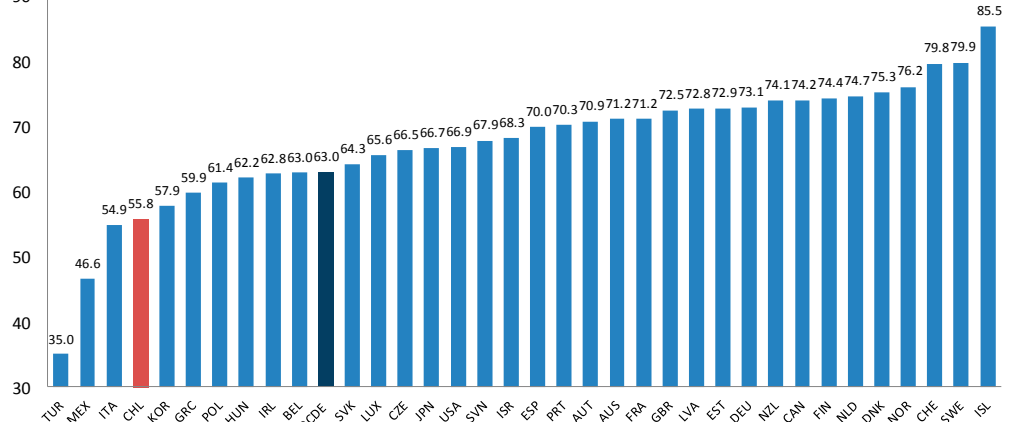

TABLA 2: AUMENTO DE UNA SOLA VEZ DE 1\% EN LOS JARDINES INFANTLES, SUPONIENDO QUE LA COMPOST-

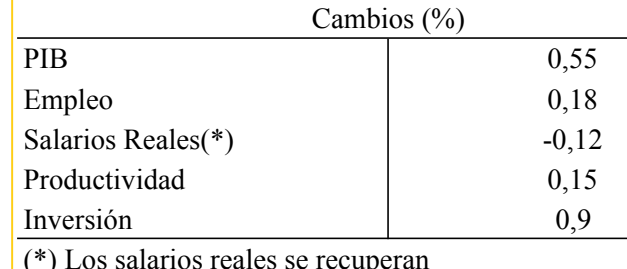

Fuente: OECD (2015).

enctuctividad

Oe
TABLA 1 MERCADO LABORAL CHLLENO, DIFERENCIAS ENTRE MUJERES Y HOMBRES

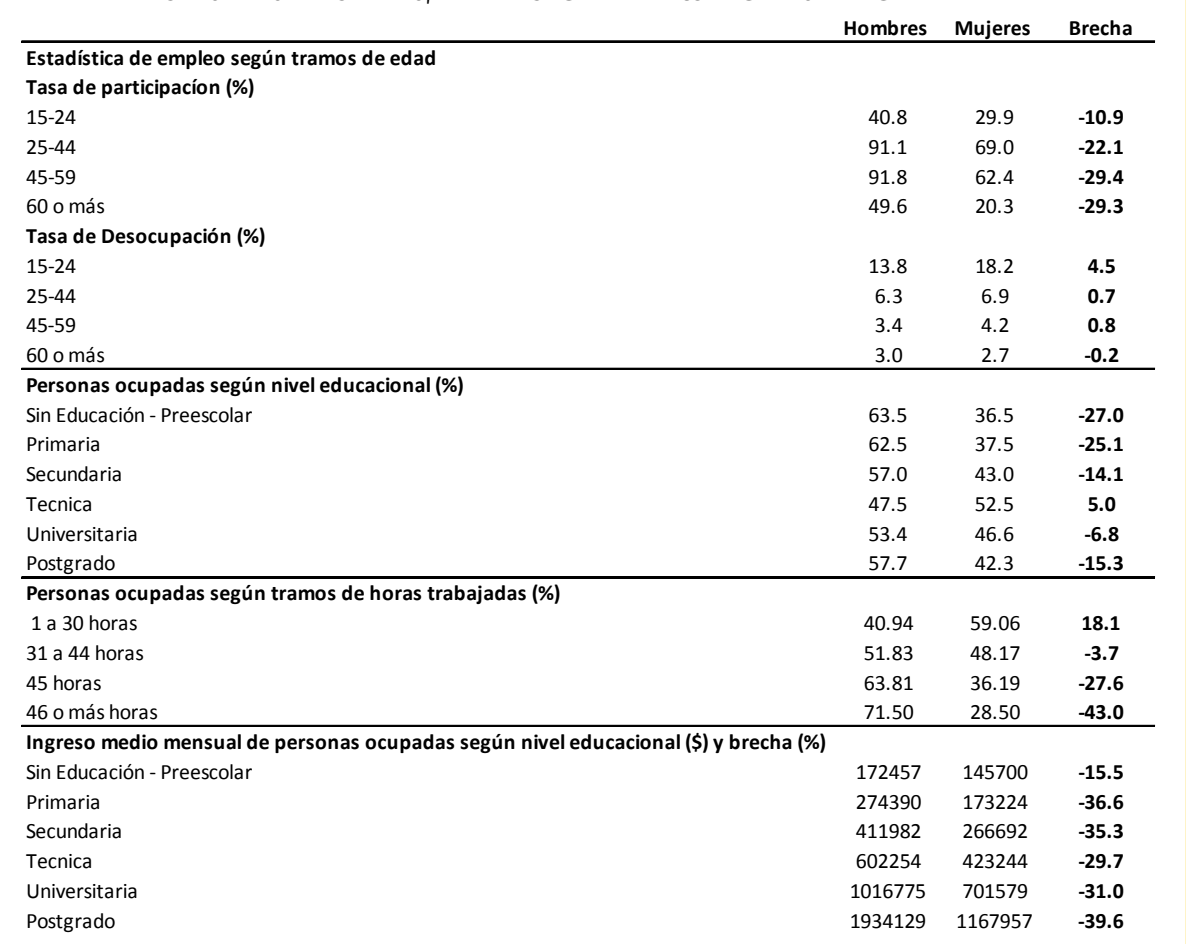

